\title{
Monstruos y ángeles en la narrativa de Pablo de Olavide*
}

\author{
Monsters and angels in the narration of Pablo de Olavide \\ Gilberto Triviños ${ }^{\dagger}$ y Edson Faúndez V. \\ Universidad de Concepción, Departamento de Español, Concepción, Chile. \\ Correo electrónico: efaundez@udec.
}

En las "novelas morales" de Pablo de Olavide, el estudio de las relaciones mediatizadas por la seducción permite apreciar la creación, proliferación y expulsión de la alteridad radical, asî como también visualizar los signos distintivos del sueño olavideano (anti)utópico por excelencia, donde domina lo que Jean Baudrillard llama la "Metástasis de lo Mismo".

Palabras clave: Pablo de Olavide, "novelas morales”, deseo, seducción, alteridad.

In the 'moral novels' of Pablo de Olavide, the study of relationships mediated by seduction allows us to appreciate the creation, proliferation and expulsion of radical alterity as well as to visualize the distinctive signs of the Olavidean dream, (anti) utopical par excellence, dominating what Jean Baudrillard calls the 'Metastasis of the Same'.

Key words: Pablo de Olavide, moral novels, desire, seduction, alterity.

Si le monstre c'est l'exclu, par excès ou par manque, par démesure dans le trop ou le pas assez, comment ne pas voir en lui non pas l'Autre d'un monde ordonné, mais l'index de vérité d'un monde qui s'efforce vainement d'occulter son désordre?

M.M. ${ }^{1}$

El rostro más conocido de Pablo de Olavide (1725-1803) es el de víctima de la Inquisición. La génesis de este rostro debe buscarse en las tensiones que en Europa se actualizan durante la segunda mitad del siglo XVIII. Allí residen los deseos que convierten al colonizador de Sierra Morena en un "personaje epónimo de la lucha por la libertad y contra el oscurantismo, pero, de otro lado, constituyó el estigma infamante para su nombre dentro de España" (Núñez 1987: XXV). La atracción seductora e

\footnotetext{
* Investigación realizada dentro del marco del proyecto MECESUP UCO 0203, "Fortalecimiento de la calidad y la innovación en la formación de doctores en literatura latinoamericana", cuyos autores integran el Grupo de Investigación "Literatura Colonial de los siglos XVI, XVII y XVIII" y el Grupo de Investigación 03.F2.04 de la Dirección de Investigación de la Universidad de Concepción.

1 “Presentación”, en: Revue des sciences humaines. Lille III. “Le Monstre”. 1982-4, 188.
} 
inquietante del mito del intelectual peruano no sólo se funda en la valoración positiva de los ilustrados, sino también en "el estigma infamante" que surge de los poderes conservadores de la época. Esa fascinación y repudio por los deseos perturbadores que singularizan la figura histórica se encuentra de algún modo también presente en su obra literaria, fundamentalmente en Evangelio en triunfo y las "novelas morales". Éstas, escritas en la etapa en que el pensamiento de Olavide arriba a una síntesis de la filosofía y la teología, despliegan un programa didáctico-moral en donde la seducción es una de las estrategias mediante las cuales se incita al lector a fabular un territorio en el que la alteridad es (ilusoriamente) anulada.

Las relaciones mediatizadas por la seducción constituyen una de las matrices textuales de mayor significación en la escritura narrativa de Pablo de Olavide. Los relatos Laura o el sol de Sevilla, Paulina o el amor desinteresado, Sabina o los grandes sin disfraz, Lucía o la aldeana virtuosa, Marcelo o los peligros de la corte, El incógnito o el fruto de la ambición y Teresa o el terremoto de Lima incluyen personajes que cumplen la función de seductores(as) o seducidos(as). La seducción se convierte en la fuerza que dinamiza estos relatos, en la medida en que promueve desplazamientos, conexiones e intercambios entre personajes de espacios axiológicos antitéticos. La narrativa del ilustrado peruano, por lo mismo, se actualiza, fundamentalmente, en una dimensión en donde los contrarios se atraen y se rechazan, afectándose mutuamente. Desde este acceso, el mal (el vicio) no es lo que se opone al bien (la virtud) en la narrativa de Olavide, sino aquello que lo seduce.

La serie de novelas morales presenta referencias directas e indirectas al problema de la seducción. El Estremeño, personaje de Laura o el sol de Sevilla, se siente atraído por la fama de Laura, cuya belleza "cautivaba las almas" y "abrasaba los corazones" (Olavide 1987: 172) ${ }^{2}$. El discurso del lenguaraz seductor, a través del cual se enuncia la supuesta traición conyugal de Laura, perturba al marqués, quien despliega juicios y acciones apresurados. El relato de la belleza y la bondad de la protagonista de Paulina o el amor desinteresado despierta la atención de todos. Lo que seduce, nuevamente, son las virtudes; en efecto, Paulina brilla por "su candor, su inocencia y su alegría", cualidades que "la hacían interesante para todos" (62). El marqués de San Leandro, hombre honrado pero con algunos vicios, no puede resistir el secreto embrujo que termina por hacerle olvidar "todas las varias diversiones, que el mundo llama placeres". La "victoria tan difícil sobre la violencia de (su) inclinación" (80), se encuentra asociada a su transfiguración espiritual, proceso en el que la virtud de Paulina resulta fundamental. Sabina y Félix, personajes de Sabina o los grandes sin disfraz, se mueven en un fondo de envidia, infamia y corrupción, el cual afecta sus vidas y provoca que no se concrete su unión. La figura del conde, personaje "insensible y de corrompido corazón" (146), es sumamente interesante, ya que es éste quien siente la fuerza atractiva de la virtud de Sabina. La "hermosura fatal ha seducido (su) corazón" (146) a tal extremo que le resulta intolerable que Sabina rehúse la invitación a ingresar al territorio del placer en donde él señorea, razón por la cual el monstruoso conde se convierte en el "pérfido robador de su honra, el sacrílego profanador de su virtud" (150). Sabina y Félix mueren, quedando establecido que en la otra vida obtendrán la justa recompensa

\footnotetext{
2 Todas las citas pertenecientes a las novelas de Olavide serán señaladas sólo con el número de página. De Olavide, Pablo. 1987. Obras selectas. Estudio preliminar, recopilación y bibliografía por Estuardo Núñez. Lima: Ediciones del Centenario Banco de Crédito del Perú.
} 
que la sociedad no pudo brindarles. Dos son los momentos en que se pone a prueba la virtud de la protagonista de Lucía o la aldeana virtuosa. Fadrique, "mozo atrevido, y de costumbres viciosas" (159), no se resiste a los naturales encantos de Lucía; sin embargo, sus galanteos no doblegan a la joven. Por otro lado, en un momento crucial del relato, Lucía se propone emplear algunas de las monedas que encontrara en una bolsa olvidada en la calle. A pesar de que "la acometen todas las seducciones del deseo" (164), ella se contiene, intensificando su condición de sujeto virtuoso. Muy sugerente es la relación que la joven entabla con la condesa de Pastrana, porque es posible percibir cómo los idénticos se atraen, cómo la virtud anula las diferencias y hace homogéneo un territorio. Marcelo o los peligros de la corte textualiza la caída y restablecimiento de la virtud del héroe. Marcelo es corrompido por el libertino marqués de Dombal y "una sirena seductora" (96), Cipriana, que, en realidad, es un "monstruo de perfidia y horror" (118). En el texto se lee: "Dos malvados me han engañado, me han seducido, me han hecho cometer mil errores" (118). En El incógnito o el fruto de la ambición, la virtud de Rufina, que "parecía un ángel descendido del cielo" (21), cautiva a un joven noble, quien se aprovecha de la ambición del padre de ésta para deshacer los esponsales concertados entre Rufina y Albano. Por último, en Teresa o el terremoto de Lima, la belleza de Teresa cautiva a don Ramiro, quien procura satisfacer su irracional inclinación, sosteniendo un matrimonio desigual.

Las tensiones en la estructura binaria de los relatos son significativas, pues iluminan a los verdaderos personajes seductores. La mujer es una potencia seductora en la novelística de Olavide. Su irrupción produce, generalmente, el olvido de la singularidad de los sujetos seducidos, porque "todo escapa a sí mismo, todo se ríe de su propia verdad, todo se escapa por el lado de la seducción” (Baudrillard 1988: 63). Los poderes económico y político suelen encantar a los personajes olavideanos; sin embargo, la joven virtuosa es la fuerza atractiva por excelencia. Laura, Paulina, Sabina, Lucía y Teresa son seductoras, porque en ellas se materializan las virtudes. Esto las hace irresistibles a libertinos, quienes buscan degradarlas; pero también a honestos varones, quienes buscan consagrarlas a través del matrimonio en la virtud y el orden. La mujer (virtuosa) seductora puede disolver la verdad del sujeto libertino, conduciéndolo a la asimilación de sus códigos de conducta. La mujer (viciosa) seductora puede disolver la verdad del sujeto virtuoso, conduciéndolo a la asimilación de sus códigos de conducta. Cipriana cifra en Marcelo o los peligros de la corte la seducción del vicio, pues cumple la función de desviar y dirigir a Marcelo hacia las moradas del vicio y la corrupción ${ }^{3}$. Paulina cifra en Paulina o el amor desinteresado la seducción de la virtud, ya que desvía al marqués de San Leandro hacia la virtud. Al parecer, Olavide advierte la condición dual inherente a la seducción, la que, como lo sugiere Baudrillard (1987), tiene relación con la síntesis del bien y del mal, del recato y de la concupiscencia, de la virtud y del vicio, lo que convertiría a la mujer en un ser indescifrable. No obstante lo anterior, en la medida en que produce una tipología de la mujer seductora, el ilustrado peruano deshace el bloque donde los contrarios se funden, para explicitar la diferencia entre la seducción que conduce al orden y la seducción erótica, causa de "un inmenso desorden" (Bataille 2004: 381); de esto deriva el que

\footnotetext{
3 Recuérdese que Jean Baudrillard en El otro por sí mismo ha señalado que la seducción "es lo que desvía, lo que aleja del camino" (1988: 61). Por ejemplo, Marcelo olvida sus obligaciones conyugales, don Ramiro abandona el ejercicio de la razón, el marqués de San Leandro ve disueltas sus ansias carnales.
} 
la seducción de la virtud sea claramente exaltada y la seducción erótica del libertino y la libertina sea sometida a rituales de expulsión ${ }^{4}$. Si se exalta la virtud de las mujeres jóvenes, es porque ello favorece la programación didáctico-moralizadora de la obra de Olavide. Piénsese que la mujer es percibida en el siglo XVIII de modo similar a como se consideró en los siglos precedentes, es decir, continúa caracterizándose por su natural debilidad a "ocultarse y caminar por vías torcidas", lo que trae como correlato que "este sexo tiene menos inclinación que el nuestro a la virtud" (Platón 1872: 306$)^{5}$. En efecto, en una sociedad que niega el cuerpo y la sexualidad, "las mujeres sólo podían aparecer como perturbadoras del orden social" (Delacampagne 1983: 204). La mujer, dada su "natural" propensión al desorden, se convierte en un notable ejemplo de cómo, mediante una correcta educación, es posible lograr que prevalezca la virtud por sobre el placer; asimismo, deviene en trofeo reservado a los que han salido airosos en los combates con las fuerzas de la negatividad que pueblan el exterior social. En los relatos de Olavide, el germen disolvente, constitutivo de la diferencia femenina, queda enjaulado, a nivel general, en las relaciones de fuerza de la sociedad patriarcal y, a nivel particular, en el codificado contrato matrimonial ${ }^{6}$. Cuando la alteridad femenina no es controlada se convierte en un peligro y en un obstáculo. La letra, entonces, ilumina y expulsa lo incalculable libre, el vicio, que reside en las figuras de la alteridad.

La seducción descalificada surge desde el territorio del vicio e intenta cautivar a sujetos virtuosos. La seducción exaltada fluye desde el territorio de la virtud e intenta, además de defender su ámbito de acción, transfigurar a sujetos en vías de corromper$\mathrm{se}^{7}$. La seducción, desde este acceso, no sólo es la estrategia que erosiona los poderes

\footnotetext{
4 Según Bataille, la moral y el erotismo se encuentran enlazados, se exigen mutuamente. El combate es lo que signa su relación: "La moral es necesariamente el combate contra el erotismo y el erotismo, necesariamente, sólo tiene lugar en la inseguridad de un combate" (2004: 382). Este combate es el que se expresa en la escritura de Olavide. Más adelante examinaremos las implicaciones de la idea de escritura como guerra continua.

5 Platón construye una imagen de la mujer sobre la base de una supuesta inferioridad biológica. En este momento, la mujer es visualizada como un obstáculo -desvía del camino de la virtud- y como un enemigo al cual es necesario vigilar -recuérdese su inclinación al desorden-. Las mujeres durante la Edad Media configuran la alteridad por excelencia: "a partir del siglo XIII la mujer no existe sino como imagen del diablo; es el propio diablo, es bruja por naturaleza antes de serlo por profesión" (Delacampagne 1983: 205). En ambas escenas, la mujer representa lo otro. Sus rostros han sido asignados mediante una serie de enunciados delirantes.

${ }^{6}$ La figura femenina se resuelve en alteridad regulada, en la medida en que es sobrecodificada por el poder; sin embargo, "en el otro se esconde una alteridad ingobernable, amenazante, explosiva; aquello que ha sido embalsamado o normalizado puede despertar en cualquier momento" (Baudrillard y Guillaume 2000: 16). Actualmente, los ingobernables poderes de las mujeres han despertado. En el siglo XVIII constituían un grupo regulado por el poder. Voltaire, por ejemplo, construye el rostro de la alteridad femenina recurriendo al antiguo bloque biológico-cultural: "El macho, por regla general, vive más tiempo que la hembra, y es siempre más grande proporcionalmente. El hombre de mayor estatura tiene ordinariamente dos o tres pulgadas de altura más que la mujer más alta; su fuerza casi siempre es superior, es más ágil y como sus órganos son más fuertes, es más capaz de prestar atención constante. Inventó él las artes, y no la mujer, y debemos considerar que no es el fuego de la imaginación, sino la meditación perseverante y la combinación de las ideas, el origen de la invención de las artes; como la pólvora, la imprenta, la relojería, etc." (1983: 196).

7 La metamorfosis del monstruo se hace efectiva en Paulina o el amor desinteresado y queda explicitada como posibilidad en Sabina o los grandes sin disfraz. Citamos un fragmento del segundo texto: "Bien sé que el conde es un malvado, un hombre injusto y vil: demasiado lo sé, pero es el único que puede protegerte, y salvar a tu esposo. Este hombre te ha querido, y quizás podrás despertar la piedad en su corazón
} 
del mal, ya que el mismo discurso olavideano también activa estrategias en las que la seducción es fundamental. La virtuosa mujer, como hemos sugerido, cifra una potencia seductora que puede desviar al individuo desde los placeres mundanos hacia el respeto de los códigos morales ${ }^{8}$. La escritura narrativa de Olavide es el resultado de una lectura de la realidad que ha tenido como consecuencia una valoración negativa de los códigos sociales imperantes, los cuales son la causa de la multiplicación del "mal moral". Su novelística funciona como resistencia a la sociedad del mal, siendo la seducción un arma con la que se persigue modificar las almas de los lectores.

En el lugar de la seducción, las verdades morales que recorren los textos se activan e imponen. Laura o el sol de Sevilla constituye un ejemplo valioso sobre la instalación y exclusión de las apariencias, es decir, la fascinación y el rechazo de la seducción. El Estremeño cree que ha vencido las fortalezas de la virtud de Laura, pero cuando se rasga el velo de la ilusión el lector descubre que el seductor ha sido burlado por Eulalia. El simulador de conquistas amorosas se desvía de su objetivo y es arrastrado hacia una superficie transparente donde lo espera la muerte. El engaño de Eulalia y el trágico final del Estremeño desencadenan el desorden en el mundo ordenado por Laura, lo que sugiere que la seducción del mal es la causa del deterioro de la estabilidad del mundo social. Además, la muerte de Laura y la culpa del marqués son pura ilusión. El relato es dominado por las apariencias, las cuales van cubriendo las profundidades de sentido que intenta recuperar Olavide. No obstante, los textos ficcionalizan la derrota de las apariencias y el restablecimiento de las zonas profundas, grávidas, en las cuales perviven los discursos que dotan de sentido a la sociedad. En esas zonas profundas, la verdad ideológica del texto aflora, se fortalece y perdura. El escritor peruano produce un territorio que actualiza ceremonias de expulsión de las apariencias, lo que repercute en el fortalecimiento de su verdad ideológica. Resulta paradójico, sin embargo, comprobar que el discurso narrativo olavideano recurre a las mismas estrategias seductoras que las empleadas por las transparentes y mutantes "fuerzas del mal".

Son seductores las figuras virtuosas y los premios obtenidos, pero también es seductor el lenguaje literario. El lenguaje es seductor no sólo porque dominen en la narración relaciones de seducción. El lenguaje de las novelas morales es seductor porque produce un placer tan "inmundo" como el que buscan los más abyectos personajes retratados. Es el mismo lenguaje seductor el que encubre y revela una verdad ideológica que pretende disolver el actual orden del mal y proponer un orden social sobre la base de las nupcias entre la teología y la filosofía ilustrada, "entre la virtud cristiana y la virtud civil"9. Las novelas morales utilizan el lenguaje para

(...) Le habla con dificultad, con fuerza, y con una sensibilidad amable, modesta y decorosa: pero ¡ay! el monstruo no sentía nada" (144).

8 Esto es posible sólo porque la mujer ha devenido en ángel, es decir, el cuerpo erótico de la mujer se transfigura, por mediación de la virtud, en cuerpo angélico: "mi hija Rufina salió corriendo y parecía un ángel descendido del cielo" (21).

9 Rolando Carrasco estudia Evangelio en triunfo y demuestra que el cambio epistemológico del pensamiento olavideano se da "dentro del propio árbol del conocimiento de la ilustración", por lo que "el movimiento desde el "filósofo ilustrado" al "filósofo desengañado" "en Evangelio en Triunfo (...) menos que una experiencia de conversión que reniega del ideal de la Ilustración -retorciendo las bases epistemológicas del árbol del conocimiento- resulta rasgo constituyente del carácter diferenciado de la Ilustración olavideana, en una hibridez de formas que borran las aparentes contradicciones de su cristianismo ilustrado" (2007: 40). 
dictar "órdenes a la vida", porque "el lenguaje no es la vida, el lenguaje da órdenes a la vida; la vida no habla, la vida escucha y espera. En toda consigna, aunque sea de padre a hijo, hay una pequeña sentencia de muerte -un veredicto-, decía Kafka" (Deleuze y Guattari 1997: 82). En el lenguaje de Olavide, por lo tanto, circulan con más intensidad verdaderas "consignas" que despliegan "órdenes a la vida". ¿Pero cómo consigue la lengua olavideana convertirse en una transmisora de consignas ${ }^{10}$ ? Es la redundancia la estrategia textual que transforma el lenguaje literario de Pablo de Olavide en un "sistema de órdenes y mandatos" mediante el cual se procura que el lector censure las costumbres viciosas y acepte la virtud cristiana como fuente de convivencia social, porque la redundancia "disminuye la cantidad de información (...) habría que suponer(la) como transmisión y repetición de órdenes y mandatos; por debajo estaría la información, el mínimo requerido para la correcta recepción de las órdenes" (Deleuze 1995: 67). La repetición de dicho sistema de órdenes se aprecia, fundamentalmente, en los prólogos y conclusiones novelescas de cada una de las novelas morales.

"El lector que al concluir esta novela no se sienta tan dulcemente interesado al amor casto, puro y virtuoso, y no deteste el libertinaje y la lujuria que tanto afean á este sentimiento necesario al hombre, este lector digo, creerá su fábula una mera ficción, imposible de encontrarse en el mundo" ("Prólogo", Paulina o el amor desinteresado: 61).

"No se oían entónces en aquel cuarto más que gritos de alegría. Paulina era amada, respetada, y todos sentían que era digna de la prosperidad de que iba á gozar (...) En efecto, el enfermo aliviándose cada instante más con dulces remedios, no tardó en restaurarse, y poco tiempo después se unió con el vínculo sagrado á su amada Paulina. ¿Quién puede describir la felicidad de amantes tan nobles, tan honestos y desinteresados? Tomasa y Doña Angela fueron sus amigas inseparables, y este matrimonio feliz se vió multiplicar en muchos bellos y amables hijos" ("Conclusión novelesca", Paulina o el amor desinteresado: 61).

"El autor da en esta preciosa novela uno de los ejemplos comunísimos de esta triste verdad. ¡Ojalá su lectura pueda servir de escarmiento y de lección á los apasionados del brillante atractivo de las grandes poblaciones! ¡Ojalá pueda ser un aviso saludable á los que el destino obliga á vivir en ellas! Tal es el fin de esta obrita" ("Prólogo", Marcelo o los peligros de la corte: 91 ).

"Marcelo hizo un justo y bien entendido uso de sus riquezas, aprendió á conocer los infelices y los necesitados, y gozó de la inefable felicidad de enjugar sus lágrimas, y de darle alivios y consuelos con sus beneficios. Martina no fue menos dichosa. Vió crecer á sus hijos en su seno, y en medio de los buenos ejemplos. La indigna Cipriana cayó en la mayor miseria, y murió en un hospital devorada de dolores y remordimientos. Dombal, no pudiendo sufrir el desprecio de la corte y del público, se vió forzado a espatriarse, y sus nuevos delitos le condujeron al suplicio, pero Marcelo y su muger gozaron de la felicidad que se permite á los mortales en la tierra. Viviéron muchos años, se amaron hasta el postrer suspiro, y murieron casi juntos, dejando una posteridad feliz y virtuosa" ("Conclusión novelesca", Marcelo o los peligros de la corte: 119).

\footnotetext{
10 El lenguaje despliega consignas, las cuales "no remiten, pues, únicamente a mandatos, sino a todos los actos que están ligados a enunciados por una 'obligación social”" (Deleuze y Guattari 1997: 84).
} 
"Esta novela ofrece un ejemplo terrible de las malas consecuencias que tiene la jactancia en los hombres. Este vicio detestable, no solamente los espone á ser víctimas de los enemigos que se suscitan ellos mismos, sino que también son el juguete de cuantos quieren abusar de su necia presuncion" ("Prólogo", Laura o el sol de Sevilla: 119).

"La reina Isabel quiso ver á Laura, y quedó tan prendada, que para no separarse de ella la nombró dama suya. El Rey Católico cuando fue á presentarse el Marques, le recibió con alegría; y habiéndole hecho contar su propia historia le dijo: ve aquí los riesgos de una lengua fácil, y de una resolución precipitada.

El marques contribuyó mucho con su valor á la toma de Granada; y el día que se rindió esa ciudad, y que los generales fuéron á congratular al monarca, este le dijo: tú me has dado una buena joya, y me la debías, porque yo te había hecho recobrar un mejor tesoro" (“Conclusión novelesca", Laura o el sol de Sevilla: 119).

Los prólogos y conclusiones novelescas de Paulina o el amor desinteresado, Marcelo o los peligros de la corte y Laura o el sol de Sevilla evidencian la presencia de la redundancia. La repetición de órdenes que orientan al lector para que produzca un sentido específico de los relatos es significativa en los prólogos. La escena en que el vicio es sancionado y la virtud premiada se reitera en cada una de las conclusiones novelescas. Por todas partes consignas, órdenes, mandatos en una escritura que no acepta otra lectura que la propuesta. El estilo olavideano se define así sobre la base de la repetición de escenas en las que el lenguaje despliega con más intensidad consignas, órdenes, mandatos. La redundancia es la estrategia textual con la que el autor busca incitar al otro a soñar una sociedad donde el mal moral no exista. Las novelas morales son dispositivos imaginarios y seductores que incitan a los lectores a fabular también con esa sociedad de hombres y mujeres justos que crece en las fronteras en que se tocan, sin excluirse, el pensamiento ilustrado y el pensamiento cristiano. También constituyen verdaderas sentencias de muerte para cualquier "verdad" que se aparte de la verdad novelesca cifrada en la redundancia de las consignas.

La desobediencia del orden simbólico es uno de los signos distintivos de la novelística de Pablo de Olavide. Su escritura escenifica cruces entre territorios y personajes heterogéneos, con la intención de mostrar y expulsar los seductores poderes del mal moral. Las alianzas entre heterogéneos, desde este acceso, resultan inaceptables, por lo que traen como correlato, generalmente, su disolución. En Teresa o el terremoto de Lima, las nupcias de don Ramiro implican el cruce entre dos personajes que difieren en sus condiciones social y etaria. El relato, que tiene zonas de encuentro con $\mathrm{El}$ sí de las niñas de Leandro Fernández de Moratín, expulsa la mezcla entre sujetos diferentes, verdadera causa del desorden que la escritura de Olavide intenta exorcizar. Los cruces, sin embargo, que no perturban el orden establecido son permitidos en la narrativa de Olavide. Lo anterior se confirma cuando observamos, por ejemplo, en Paulina o el amor desinteresado, en Teresa o el terremoto de Lima o en Lucía o la aldeana virtuosa que la virtud se convierte en un arma para anular las diferencias sociales ${ }^{11}$.

11 En la primera novela, Paulina, plebeya, se casa con el marqués de San Leandro; en la segunda, don Álvaro se rinde al amor que le produce la criolla Teresa Fuentes, viuda de don Ramiro, su tío; en la tercera, la virtud de Lucía es reconocida por la condesa de Pastrana, quien termina por considerarla como a su igual (es cierto que la virtud de Lucía está asociada a su origen noble). 
La idea expresada en Paulina o el amor desinteresado, según la cual "los pobres no deben salir de su esfera" (93), se debilita al percibir que la virtud iguala a todos los hombres. La virtud se convierte en la verdadera fuerza atractiva, no sólo porque es lo deseado, sino porque deviene en una fuerza unificadora y homogeneizadora. La utopía ilustrada-cristiana, implícita en "las novelas morales", imagina una sociedad de hombres y mujeres virtuosos, cuya "contraimagen de la realidad vigente" (Aínsa 1999: 32) 12 $^{2}$ establece la marginación de los seducidos por las potencias desestabilizadoras y heterogeneizadoras del mal. En el pensamiento de Olavide, el mal se expresa como desafío, es decir, "como una incitación a pensar más y de otra manera" (Ricoeur 2007: 59). Esta incitación es la que le permite enriquecer su sabiduría sobre el mal mediante la puesta en diálogo de la filosofía ilustrada y la teología. La resistencia al mal se expresa, indudablemente, en la dimensión ética, política y emocional que abre el lenguaje seductor y redundante.

En las novelas de Olavide se manifiesta una guerra entre los contrarios irreductibles. La perpetua militia interior ${ }^{13}$ adquiere un nuevo sentido, en la medida en que la letra produce los signos constitutivos de un enemigo interno que altera el orden de la polis. La noción de guerra desplegada en la escritura del novelista corresponde a la que desde el siglo XVII ha cristalizado en discursos y prácticas diversas, a saber, la guerra sistemática contra un adversario, cifra de la alteridad a conquistar o expulsar ${ }^{14}$, que divide a la sociedad en dos: nosotros y los otros. La guerra perpetua entre las figuras del bien y del mal implica renuncias, transfiguraciones, conversiones, arrepentimientos y muertes; además, sugiere que el adversario es un enemigo latente, por lo que puede resurgir en escenas distintas con un rostro diferente. El adversario es una producción discursiva, un efecto retórico, que surge en conexión con los poderes normalizadores de la sociedad. El otro, por lo mismo, es antes que cualquier cosa un cuerpo-escritura que se articula a partir de la reunión de una serie de enunciados, fundamentalmente, denigrantes. En la escritura olavideana, los hombres, en apariencia, nacieron desnudos, libres y bondadosos; pero fueron corrompidos por la sociedad ${ }^{15}$, "porque no pudieran corromperse si no tuvieran alguna bondad" (San Agustín 1964: 168). Los monstruos olavideanos son cuerpos imaginarios que despliegan deseos que perturban los valores de su mundo utópico: "Desde aquel instante todos los monstruos que acompañan al vicio, se apoderaron de mi corazón" (110). No existe una correspondencia entre la biología y lo cultural que justifique la presencia del otro, el cual debe ser percibido sólo como imagen del mal.

\footnotetext{
12 Según Aínsa, la utopía implica, además de la "contraimagen crítica", la exposición de una "visión alternativa”, en la cual estalla el lugar de ninguna parte de la utopía.

13 En "Las zahúrdas de Plutón”, uno de los textos de Los sueños, Quevedo escribe: “Advertí que la vida del hombre es guerra consigo mismo y que toda la vida nos tienen en armas los enemigos del alma, que nos amenazan más dañoso vencimiento" (1945: 48). Quevedo llama a este enfrentamiento "perpetua militia".

14 Michel Foucault en Genealogía del racismo. De la guerra de razas al racismo de Estado examina este problema: "Estamos entonces en guerra los unos contra los otros: un frente de batalla atraviesa toda la sociedad, continua y permanentemente, poniendo a cada uno de nosotros en un campo o en otro. No existe un sujeto neutral. Somos necesariamente el adversario de alguien” (1992: 59).

15 En este punto, Olavide sigue las ideas de Rousseau sobre los derechos naturales del hombre. Diferente es el pensamiento de Voltaire: "La sociedad no ha degenerado al hombre; el alejamiento de ella es lo que le degrada. El que viviera absolutamente solo perdería pronto la facultad de pensar y la de expresarse, y llegaría a convertirse en bestia" (1983: 199).
} 
La palabra "monstruo" viene de monstrare (mostrar), por lo que la producción de monstruos se encuentra asociada al afán de hacer visible y legible algo anormal que se oculta en el interior de los individuos y de la sociedad: el deseo transgresivo. Las novelas de Olavide crean monstruos, verdaderas metáforas que muestran o señalan hacia las alteridades radicales, "hacia Satanás más que hacia Dios" (Delacampagne 1983: 77) ${ }^{16}$, hacia el enigma del mal. Del mismo modo, los sujetos perversos, abyectos, monstruosos expresan "un límite escandaloso, el punto de derrumbe de la ley (...) donde lo excepcional y lo prohibido se comunican" (Foucault 2000 $:$ : 61). El otro monstruoso es una ficción que infringe las leyes que preservan el orden de Dios en la dimensión social. Foucault destaca así su emergencia entre fines del siglo XVIII y principios del siglo XIX:

"La figura del criminal monstruoso, la figura del monstruo moral, va a aparecer bruscamente, y con una exuberancia muy viva, entre fines del siglo XVIII y principios del XIX. Va a hacerlo en formas de discursos y prácticas extraordinariamente diferentes. El monstruo moral estalla en la literatura, con la novela gótica, a fines del siglo XVIII. Estalla con Sade" $\left(2000_{\mathrm{b}}: 82\right)$.

La proliferación de los perturbadores personajes sadeanos tiene un carácter distinto al que se puede percibir en la novelística del escritor peruano. Olavide comienza a producir sus novelas cortas una vez concluida la escritura de El Evangelio en triunfo (1796), por lo que es pertinente plantear, como lo propone Estuardo Núñez (1987), que aquéllas concretizan en clave narrativa las proposiciones éticas desplegadas en ésta. La crítica ha destacado los vínculos que existen entre la escritura novelística de Olavide y las novelas sentimentales de Richardson. Es necesario insistir, no obstante, en un aspecto de sumo interés. Diderot en su "Elogio de Richardson" sugiere que las obras del escritor inglés "elevan el espíritu, conmueven el alma, exhalan por todas partes el amor al bien" (1971: 90). Las novelas ya no fabulan "aventuras tan insulsas" colmadas de "prodigios disparatados" (Montesquieu 1944: 227), cuya lectura "era peligrosa para el gusto y las costumbres" (Diderot 1971: 90). En la segunda mitad del siglo XVIII, por el contrario, domina en Europa "la novela entre moralizante y racionalista (...) (que) quiere ser el reflejo de ideas que se pudieran aplicar a la vida, esto es, recetas morales que sirvan a la conducta de los hombres o al ordenamiento y mejora de la sociedad" (Núñez 1987: XLI). Las narraciones de Olavide, como las de Richardson, intensifican todo lo que es "recto y honesto y con virtud" (Cicerón 1944: 192). Son verdaderos artefactos imaginarios y disciplinarios que procuran afectar a los lectores, en el sentido de "hacer impresión una cosa en una persona, causando en ella alguna sensación" (Diccionario de Autoridades 1911: 145), para convertirlos en individuos útiles y dóciles a las expectativas de una polis que se encuentra en el porvenir ${ }^{17}$.

\footnotetext{
16 Christian Delacampagne señala que el monstruo es una metáfora que desde el siglo XIII señala hacia Satanás más que hacia Dios.

17 Mecanismos disciplinarios de control del cuerpo reticulan el escenario social, normalizando las conductas de hombres y mujeres; toda una tecnología opera sobre los cuerpos, con la intención de producir las señas de un individuo. Michel Foucault ha denominado poder disciplinario a esta fuerza que actúa sobre el cuerpo de los individuos, fijando una identidad común a partir de un minucioso proceso de aprendizaje disciplinario. La anatomopolítica del detalle, desplegada por las instituciones, corta y produce flujos con-
} 
El monstruo moral representa, por consiguiente, la alteridad radical, o sea, el rostro del otro que es "inasimilable, incomprensible e incluso impensable" (Baudrillard y Guillaume 2000: 12). Los personajes monstruosos, por una parte, pueden ser reducidos e integrados, aceptando los juegos de saber y de verdad, a la dimensión marcada como positiva por la máquina axiológica de la novelística olavideana; por otro lado, si persisten en su especificidad, los textos sancionan su diferencia con el rechazo y la expulsión. La percepción del monstruo es siempre imaginaria; pareciera ser, sin embargo, que el desorden que los signa es inmanente a la sociedad que los crea. Su exterminio, entonces, debe comprenderse como el cumplimiento de su sino fatal, o sea, creaciones destinadas a la destrucción. El monstruo deviene así en imaginaria víctima sacrificial a partir de la cual una sociedad es capaz de purificarse de su escandaloso desorden interior. Esta sociedad que respira sobre la base del derecho de monstrificar la diferencia encuentra así en el deseo etnófago la forma y las estrategias para relacionarse con el otro. Sabemos, empero, que la valoración de la realidad social realizada por Olavide es negativa. Si no es únicamente la sociedad la que de modo simbólico exorciza su desorden interior, entonces también en el propio autor residen los demonios que intenta expulsar y los ángeles que intenta conjurar.

San Agustín expresa en Confesiones que la maldad es un desorden de la voluntad y la causa del alejamiento de $\operatorname{Dios}^{18}$. En Las confesiones, Rousseau advierte que "las pasiones bajas no subyugan sino a los hombres pequeños, y hacen poca mella en las almas de gran temple" (1964: 543). San Agustín y Rousseau -en los siglos IV y XVIII respectivamente- generan dos claves que ayudan a explicar la relación del mal con las figuras de la alteridad radical. El mal sólo se manifiesta cuando domina un desorden en la voluntad, el cual se materializa en descontrol y liberación de las pasiones más bajas. Lo revocado es, entonces, la contención o la moderación, ya que "la virtud se encuentra mil veces más fácilmente en la proporción y en la igualdad que en los extremos" (Platón 1872: 293) ${ }^{19}$. El monstruo es aquél que se ha desviado de la virtud y se ha dejado seducir por las más bajas pasiones. Las síntesis monstruosas, la profanación de lo sagrado, los deseos desenfrenados que deshacen el imperio de la ley, entre otros aspectos, singularizan el transparente territorio del mal en donde se desplazan las figuras de la alteridad radical. En "La historia de la Revolución Francesa", capítulo o fragmento censurado de El evangelio en triunfo (1796), se lee:

"El hecho es que, en pocos días, todos los ricos y sumptuosos templos de París y de la Francia entera no solo quedában yermos y desnudos, sino que se destináron á usos prófanos,

ductuales, "aumentando las fuerzas del cuerpo (en términos económicos de utilidad) y disminuyendo esas mismas fuerzas (en términos de desobediencia)" (Foucault 2000a: 142). Desde este acceso, el discurso literario, eventualmente, puede funcionar como un dispositivo imaginario disciplinario. Para amplificar este problema, recomendamos la lectura de Rodríguez y Triviños (Editores). 2006. Utopía y mentira de la novela panóptica. Concepción: Editorial Universidad de Concepción.

18 El texto de San Agustín expresa: "Busqué también qué cosa era la maldad, y no hallé que fuese sustancia alguna, sino un desorden de la voluntad, que se aparta de la sustancia suma que Vos sois, Dios mío, y se ladea y une a las criaturas inferiores, que desecha y arroja todos sus bienes interiores, y se muestra en lo exterior soberbia y orgullosa" (1964: 172).

19 Aristóteles escribe en Ética a Nicómaco: "Porque lo bueno moderado, siendo y consistiendo en alguna cosa justa, es un justo más perfecto, y no es mejor que lo justo como cosa de género diverso. De manera que todo es una misma cosa lo justo y lo bueno moderado, porque siendo ambas a dos cosas buenas, es más perfecto lo justo moderado" (2000: 176). 
los unos á almacenes, los otros a caballericas, y los que no tenían destinación particular por regla general quedaban consagrados á usos políticos. En ellos se leían al pueblo las leyes del Gobierno; en ellos se tenían las Asambleas populares de que los Jacobinos eran el alma, los oradores y los maestros; en ellos se celebraban las fiestas cívicas ó profanas y así se vió la desolación y abominación en el santuario.

Quíen tandrá el valor para describir estas fiestas escandalosas y oscenas que sucediéron á las reverentes adoraciones y sacrificios de los cristianos? En vez de los salmos y cánticos sagrados que oyéron tántas veces aquellos santos muros ya no escuchaban sino los (fol. 9-2) himnos nuevos que había inventado la licencia con el pretexto de cantar la libertad. Himnos sacrílegos, que no contenían mas anatemas y blasfemias contra Dios, la Religión, sus ritos, sus ministros y contra todos los Reyes y Soberanos de la tierra.

Ya no veian mas que fiestas lúbricas que acababan todas por danzas lascivas en que reynaba la más escandalosa disolución, por que no se componian mas que de mujeres prostitutas y mozos relajados, autorizados á todas las licencias por el nuevo orden moral que se les predicaba" (Olavide 1987: 455) ${ }^{20}$.

El fragmento anterior aclara la relación que Olavide establece con la Revolución Francesa. El mito solar de la revolución -que cautivó a poetas como William Blake ${ }^{21}$ se desvanece, cuando se examinan las consecuencias del acontecimiento de 1789. En el lugar consagrado a Dios, donde reinaban sólidas bases morales que impedían los excesos y garantizaban el orden social, dominan ahora el sacrilegio, "la escandalosa disolución" y una "nueva moral", adecuada a los deseos de "mujeres prostitutas y mozos relajados". La revolución se transforma en un acontecimiento inaudito, por el cual sólo es posible experimentar pavor. El autor de El Evangelio en triunfo siente el mismo terror a los flujos desbordados del deseo y a las síntesis monstruosas que aquel miedo que lleva a Benito Pérez Galdós, en La fontana de oro, a concluir que "estas iniquidades, proyectadas por pocos y llevadas a cabo por muchos con la sencillez propia de las turbas engañadas, son muy frecuentes en las revoluciones" (1970: 293). El autor de El Evangelio en triunfo y el autor de Fortunata y Jacinta coinciden así, al menos, en el horror a la "escandalosa disolución", a "las iniquidades", a los flujos desbordados del deseo que acompañan las revoluciones. Las mujeres y los mozos que encuentran una ocasión propicia para la vida libertina en el desorden que progresa luego de los alaridos de la batalla serán repudiados, del mismo modo que son vituperados los personajes viciosos en la novelística del escritor peruano. La revolución, al transgredir los códigos establecidos del entramado social y mezclar de modo obsceno los heterogéneos, se transfigura en el acontecimiento abominable por excelencia. El marqués de Dombal, Cipriana, El Estremeño, Felipa, el infame conde de Sabina o los grandes sin virtud son juzgados y sancionados, pues desordenan la normalizada Civitas Dei que intenta dibujar Pablo de Olavide.

La palabra señala y acusa los excesos del período revolucionario. De esta manera se explica la construcción y violenta expulsión del otro en la narrativa olavideana.

\footnotetext{
20 La cita respeta la ortografía original del texto.

21 Blake en The French Revolution (1791) intensifica el mito solar de la revolución: "Sin embargo, los calabozos se estremecen y tiemblan. Los prisioneros alzan los ojos y tratan de gritar; escuchan, ríen en su lúgubre caverna; después callan, y una luz rodea los sombríos torreones. Pues los diputados del Tercer Estado se reúnen en la Sala de la Nación: semejantes a espíritus flameantes en los pórticos espléndidos del sol, prestos a sembrar la belleza en el abismo desierto y hambriento, vierten su resplandor sobre la ciudad ansiosa" (Cit. en Starobinski 1988: 27-28).
} 
El otro (el vicioso) es demonizado en el programa didáctico-moralizante de estas novelas. Constituye una conciencia que de ningún modo puede considerarse un Tú con derecho a participar en un diálogo. La narrativa de Olavide que se singulariza ética, política y estéticamente por las relaciones de seducción, la redundancia de escenas mediante las cuales el lenguaje despliega consignas de muerte, la negación de la alteridad que los mismos relatos crean y la clausura del mundo representado y los personajes representados, es, por lo tanto, monológica, en el sentido propuesto por Mijaíl Bajtín en Yo también soy (fragmentos del otro):

\begin{abstract}
“(la forma monológica) rechaza la existencia al exterior de sí mismo de otra conciencia con iguales derechos a responder, de otro yo con plenos derechos (un Tú). En una aproximación monológica (limítrofe o depurada), el otro permanece plenamente tan sólo como objeto de la conciencia, pero no como otra conciencia. El monólogo es concluso y sordo hacia la respuesta ajena, no la espera y no reconoce su fuerza decisiva. El monólogo se las arregla sin el otro y por lo mismo en cierta medida cosifica a toda la realidad. El monólogo pretende ser la última palabra. Clausura el mundo representado y a las personas representadas" (2000: 164).
\end{abstract}

Las novelas de Olavide operan como un potente dispositivo para modificar espíritus sobre la base de un programa moral preestablecido. También representan una fuente de seducción que da muerte simbólica al otro fabulado en la narración y desea dar muerte a la verdad del otro-lector en la recepción estética del relato. Existe, empero, otro nivel que resulta sugerente. La narrativa de Olavide constituye un verdadero llamado a un pueblo que ha sido disgregado por las ideas de los enciclopedistas y el proceso revolucionario. Ese pueblo ausente es el que intenta congregar o reinventar el intelectual peruano. Mientras aguarda que su deseo cristalice, Olavide se repliega en la reformulación de ciertas consignas que en otro tiempo consideró pura palabra vacía, pero también escribe para los enfermos a quienes seduce con una cura que exige de ellos el sacrificio en la virtud ${ }^{22}$.

La etapa final de la obra de Pablo de Olavide, en la que incluimos las obras analizadas, puede considerarse como el momento de máximo esplendor de su lucidez o como una época gobernada por el desencanto, el miedo y la tristeza. Tal vez el último rostro de la escritura de Olavide corresponda al rostro del "refugio donde se retira el filósofo, cansado, helado por la edad" (Nietzsche 1995: 243). La sabiduría moral se convierte así en la guarida del ilustrado herido, doblegado por el incumplimiento del ideario de libertad, igualdad y fraternidad ${ }^{23}$, pero, paradójicamente, más fascinado que nunca con las promesas de las consignas ilustradas. La toma de la Bastilla no logró extirpar la inclinación al vicio, entonces propiedad de los aristócratas libertinos. Instaló, por el contrario, esta enfermedad en toda la red social. Olavide, siguiendo a

\footnotetext{
22 Diderot en "Elogio de Richardson” advierte la vinculación entre virtud y sacrificio: “Qué es la virtud? Es, bajo cualquier aspecto que se considere, un sacrificio de sí mismo" (1971: 92).

23 Pedro Henríquez Ureña describe con precisión la fascinación y el rechazo que Olavide experimenta por la Revolución Francesa: “Al estallar la Revolución seguía disfrutando de la mejor reputación; la Convención le nombró ciudadano adoptivo de la República, y votó para él una corona cívica. Pero fueron pocos los que lograron salir con bien de aquél torbellino. Olavide fue encarcelado en 1974. Renegó entonces de su credo filosófico y se hizo devoto, escribió su autobiografía, El Evangelio en triunfo, que alcanzó extraordinaria difusión, y vertió al español, en verso, los Salmos y muchos himnos medievales" (1954: 92).
} 
Sócrates, sostiene que la virtud puede ser enseñada; cree, como Platón, que los remedios fundamentales para subvertir el gobierno del placer son el respeto a la ley, los poderes de la razón, el auxilio de Dios y el temor ${ }^{24}$. Sus novelas son una síntesis de estas cuatro dimensiones. La escritura literaria adquiere una significación doble: espacio donde la palabra busca convertirse en vehículo para educar y espacio que hace posible, al decir de Piglia, "una forma privada de la utopía" (2000: 102). El sabio moralista sueña una sociedad donde las diferencias son anuladas por mediación de la virtud. Una sociedad de ilustrados cristianos, ${ }^{25}$ donde la clave continúa siendo la anulación del otro y la repetición de lo idéntico. Metástasis de lo Mismo que borra ilusoriamente lo que Baudrillard denomina en La transparencia del mal la "regla de juego del mundo" (1991: 158): la indestructibilidad de la alteridad radical: "la Alteridad radical resiste a todo: a la conquista, al racismo, al exterminio, al virus de la diferencia, al psicodrama de la alienación. De una parte, el Otro siempre está muerto: de la otra, es indestructible" (1991: 156). La narrativa monológica olavideana no descubre en la desnudez del rostro del otro -el adversario- la fuerza que reúne lo heterogéneo: la idea de lo Infinito ${ }^{26}$; y, por consiguiente, su autor es incapaz de leer la escritura secreta inscrita en el rostro del otro: "no matarás". La utopía de Olavide deviene así en antiutopía porque clausura con el gesto de aniquilación simbólica del otro el mismo porvenir. Las novelas morales intensifican así el mal que pretenden eliminar, ya que la elección por el bien sólo es imaginable cuando lo exaltado es "la no-violencia misma" (Levinas 2006: 103). Sólo pueden anunciar por ello un destino funesto, pues los individuos y los sistemas "autoprogramados y referenciales", como advierte Baudrillard (1997: 153), enfrentados a un panorama en el que el adversario y el entorno hostil han sido eliminados, están condenados a desaparecer.

La alteridad, ya lo sabemos, es siempre indestructible. Los monstruos que segrega la tristeza continúan proliferando en la antiutopía olavideana, cuya oculta verdad es la metástasis del mal. Su (imposible) destrucción proyecta una ilusión de estabilidad en la convulsionada alma de Pablo de Olavide.

\footnotetext{
24 Platón en Las leyes señala que los remedios para el placer "son el temor, la ley y la recta razón, a los que debe unirse el auxilio de las Musas y el de los dioses que presiden a los combates" (1872: 309).

25 Rousseau define como quiméricas a las sociedades conformadas sólo por cristianos: "Se nos dice que un pueblo de verdaderos cristianos formaría la más perfecta sociedad que se puede imaginar. No veo en esta suposición más que una dificultad: que una sociedad de verdaderos cristianos no sería una sociedad de hombres. (...) Para que la sociedad fuese pacífica y la armonía se mantuviese, sería preciso que todos los ciudadanos, sin excepción, fuesen igualmente buenos cristianos; pero si, desgraciadamente, surge un solo ambicioso, un solo hipócrita, un Catilina o, por ejemplo, un Cromwell, seguramente daría al traste con sus piadosos compatriotas" (163-164).

26 Emmanuel Levinas en Humanismo del otro hombre escribe: "El Yo ante Otro es infinitamente responsable. El Otro que provoca este movimiento ético en la conciencia, que desajusta la buena conciencia de la coincidencia del Mismo consigo mismo, implica un acercamiento inadecuado a la intencionalidad. Esto es el Deseo: arder en un fuego distinto a la necesidad que la saturación apaga. Pensar más allá de lo que se piensa. A causa de este acrecentamiento inasimilable, a causa de este más allá, hemos llamado a la relación que une el Yo y el Otro idea de lo Infinito" (2006: 66).
} 


\section{OBRAS CITADAS}

Aínsa, Fernando.1999. La reconstrucción de la utopía. México: Ediciones UNESCO.

Aristóteles. 2000. Ética a Nicómaco. Vol. I, Navarra: Ediciones Folio.

Bajtín, Mijaíl. 2000. Yo también soy (fragmentos sobre el otro). México, D. F.: Editorial Taurus.

Baudrillard, Jean. 1987. De la seducción. Buenos Aires: R.E.I.

Baudrillard, Jean. 1997. El crimen perfecto. Barcelona: Anagrama.

Baudrillard, Jean. 1988. El otro por sí mismo. Barcelona: Anagrama.

Baudrillard, Jean.1991. La transparencia del mal. Barcelona: Anagrama.

Baudrillard, J.; Guillaume, M. 2000. Figuras de la alteridad. México: Taurus, La huella del otro.

Carrasco, Rolando. 2007. "Un mito en movimiento: Pablo de Olavide y su Evangelio en Triunfo (1797)". Revista Chilena de Literatura, № 71: 19-42.

Cicerón, Marco Tulio. 1944. La República. Las Paradojas. Buenos Aires: Editorial GLEM.

Delacampagne, Christian. 1983. Racismo y Occidente. Barcelona: Editorial Argos Vergara.

Deleuze, Gilles. 1995. Conversaciones. 1972-1990. Valencia: Pre-Textos.

De Olavide, Pablo. 1987. Obras selectas. Estudio preliminar, recopilación y bibliografía por

Estuardo Núñez. Lima: Ediciones del Centenario Banco de Crédito del Perú.

De Quevedo, Francisco. 1945. Los sueños. Buenos Aires: Espasa-Calpe Argentina, S. A.

Deleuze, G. y Guattari, F. 1997. Mil mesetas. Capitalismo y esquizofrenia. Valencia: PreTextos.

Diderot, Denis. 1971. Textos para una estética literaria. Selección, traducción, prólogo y notas de Kart Yung y Zaida Yung. Santiago de Chile: Editorial Universitaria.

Foucault, Michel. 2000a. Defender la sociedad. Buenos Aires, Fondo de Cultura Económica de Argentina.

—. 2000b. Los anormales. Buenos Aires: Fondo de Cultura Económica de Argentina, S.A.

—. 1992. Genealogía del racismo. De la guerra de razas al racismo de Estado. Madrid: Las Ediciones de la Piqueta.

Henríquez Ureña, Pedro. 1954. Las corrientes literarias en la América Hispánica. México, D.F.: Fondo de Cultura Económica.

Levinas, Emmanuel. 2006. Humanismo del otro hombre. México: Siglo Veintiuno Editores.

Montesquieu. 1944. Cartas persas. Buenos Aires: Ediciones Siglo Veinte.

Nietzsche, Friedrich. 1995. La gaya ciencia. Madrid: M. E. Editores S. L.

Núñez, Estuardo. 1987. "Estudio preliminar”. En: De Olavide, Pablo. 1987. Obras selectas. Lima: Ediciones del Centenario Banco de Crédito del Perú.

Pérez Galdós, Benito. 1970. La fontana de oro. Madrid: Alianza Editorial.

Piglia, Ricardo. 2000. Crítica y ficción. Buenos Aires: Seix Barral.

Platón. 1872. Obras completas. Tomo IX. Las leyes. Madrid: Medina y Navarro Editores.

Ricoeur, Paul. 2007. El mal. Un desafío a la filosofía y la teología. Buenos Aires-Madrid: Amorrortu Editores.

Rousseau. 1975. Contrato social. Madrid: Espasa-Calpe.

San Agustín. 1964. Confesiones. Barcelona: Editorial Iberia, S.A.

Starobinski, Jean. 1988. 1789, Los emblemas de la razón. Madrid: Taurus.

Voltaire. 1983. Cartas filosóficas y otros escritos. Madrid: Sarpe.

VV. AA. 1982. Revue des sciences humaines. Lille III. "Le Monstre", 188. 